\title{
AVALIAÇÃO DO POTENCIAL DA PLANTA ADIANTUM CAPILLUS-VENERIS (L.) NO CONTROLE DE FITOPATÓGENOS
}

\author{
A.P. Formighieri ${ }^{1}$, J.R. Stangarlin ${ }^{1 *}$, C.C. Meinerz ${ }^{1}$, G. Franzener ${ }^{1}$, K.R.F. Schwan-Estrada ${ }^{2 *}$ \\ ${ }^{1}$ Universidade Estadual do Oeste do Paraná, Centro de Ciências Agrárias, CP 91, CEP 85960-000, Marechal \\ Cândido Rondon, PR, Brasil. E-mail: jrstangarlin@pq.cnpq.br
}

\section{RESUMO}

O uso de compostos secundários de plantas medicinais, com propriedades antimicrobianas, pode ser uma alternativa para o controle de fitopatógenos. Diante disso, este trabalho teve como objetivo avaliar a atividade antimicrobiana de derivados obtidos da planta Adiantum capillusveneris (avenca) contra fungos e bactérias fitopatogênicos. Os derivados, obtidos do pó de folhas de avenca secas ao ar, foram preparados por infusão, maceração e decocção, autoclavados ou não, nas concentrações de 0,1\%, 0,25\%, 0,5\%,1\%,1,25\%,2,5\%, 5\%, 10\% e 20\%. Foram avaliadas a germinação de esporos dos fungos Phakopsora euvitis e Pseudocercospora vitis, o crescimento micelial dos fungos Colletotrichum musae e Sclerotium rolfsii e a multiplicação das bactérias Erwinia sp. e Bacillus subtilis. O extrato obtido por maceração não autoclavado foi o que apresentou maior efeito sobre $P$. euvitis e $P$. vitis com reduções de $75 \%$ e $99 \%$ na germinação de esporos na concentração de $20 \%$, respectivamente. O menor crescimento micelial de C. musae e $S$. rolfsii foi obtido pelo macerado autoclavado, com redução de 39\% e 83\%, respectivamente. Para Erwinia sp., o maior efeito inibitório foi obtido com o macerado autoclavado que, na concentração de $25 \%$, inibiu $99 \%$ a multiplicação bacteriana. Para B. subtilis, não houve inibição significativa. Esses resultados indicam o potencial de derivados de avenca para o controle de fitopatógenos.

PALAVRAS-CHAVE: Controle alternativo, planta medicinal, decocção, maceração, infusão.

\begin{abstract}
EVALUATIONOF THE POTENTIALOF THEMEDICINAL PLANT ADIANTUMCAPILLUSVENERIS(L.) FOR THE CONTROL OF PHYTOPATHOGENS. The use of secondary compounds of medicinal plants, with antimicrobial properties, can be an alternative for the control of phytopathogens. The aim of the present study was to evaluate the antimicrobial activity of derivatives obtained from the medicinal plant Adiantum capillus-veneris (maidenhair fern) against phytopathogenic fungi and bacteria. The derivatives, obtained from the powder of shadow-dried maidenhair fern leaves, were prepared by infusion, maceration and decoction, autoclaved and non-autoclaved, in the concentration of $0.1 \%, 0.25 \%, 0.5 \%, 1 \%, 1.25 \%, 2.5 \%, 5 \%, 10 \%$, and $20 \%$. The germination of Phakopsora euvitis and Pseudocercospora vitis spores, the mycelial growth of Colletotrichum musae and Sclerotium rolfsii, and the multiplication of Erwinia sp. and Bacillus subtilis bacteria were evaluated. The extract obtained by non-autoclaved maceration presented the best effect against P. euvitis, with reduction of $75 \%$ on uredospores germination in the concentration of $20 \%$. Against P. vitis, the derivative obtained by non-autoclaved maceration was more effective, presenting $99 \%$ of reduction on conidia germination in the concentration of $20 \%$. The smallest mycelial growth of C. musae and S. rolfsii was obtained by autoclaved maceration with $39 \%$ and $83 \%$ reduction, respectively. For Erwinia sp., the greatest inhibitory effect was obtained with the $25 \%$ autoclaved maceration that inhibited the bacterial growth at $99 \%$. For B. subtilis, there was no significant inhibition. These results indicate the potential of maidenhair fern derivatives for the control of phytopathogens.
\end{abstract}

KEY WORDS: Alternative control, medicinal plant, decoction, maceration, infusion.

${ }^{2}$ Universidade Estadual de Maringá, Maringá, PR, Brasil.

*Bolsistas CNPq.

Arq. Inst. Biol., São Paulo, v.77, n.3, p.487-496, jul./set., 2010 


\section{INTRODUÇÃO}

Com o crescente desenvolvimento de tecnologias voltadas para a agricultura, são evidentes os incrementos na utilização de insumos, em especial de pesticidas. O uso de pesticidas vem contribuindo para o aumento da produtividade agrícola, mas também tem sido responsável por efeitos adversos sobre o meio ambientee a saúde humana (STANGARLIN et al., 1999). Isso se traduz pelo acúmulo de resíduos tóxicos ao longo da cadeia trófica, com impactos em longo prazo e danos a flora e a fauna, bem como às atividades produtivas diretamente dependentes de uso de recursos naturais, à vida selvagem, a piscicultura, aos insetos benéficos e mesmo ao homem (Borem, 2001). Além disso, o alto custo, o aumento da resistência dos fitopatógenos a esses produtos químicos (GHINI; KIMATI, 2000) e a conscientização do consumidor na procura de alimentos sem resíduos de pesticidas, têm levado à necessidade de se obter produtos alternativos para controle de doenças em plantas (NAKASONE et al., 1999).

As plantas medicinais possuem compostos secundários que tanto podem ter ação fungitóxica (ação antimicrobiana direta) (SCHWAN-ESTRADA et al., 2003) como elicitora, ativando mecanismos de defesa nas plantas (ação indireta) (SCHWAN-EsTRADA; STANGARLIN, 2005). Na literatura é possível encontrar vários trabalhos que utilizam as propriedades antimicrobianas dos compostos secundários de plantas medicinais para ocontrole deagentes fitopatogênicos, como de Achillea millefolium, Cymbopogon citratus, Eucalyptus citriodora e Ageratum conyzoides contra Didymella bryoniae (FIORI et al., 2000), de Baccharis trimera contra Staphylococcus aureus e Streptococcus uberis (AvANCINI et al., 2000), de Artemisia camphorata contra Bipolaris sorokiniana (FRANZENER et al., 2003), de E. citriodora contra Colletotrichum lagenarium (BONALDO et al., 2004), de Curcuma longa contra Alternaria solani (BAlBI-PeÑaetal.,2006) econtra Xanthomonas axonopodis pv manihotis (KuHN et al., 2006) e de Zingiber officinalis contra Helminthosporium spp. (RODRIGUEs et al., 2006).

A avenca (Adiantum capillus-veneris L.), também conhecida como cabelo de Vênus, é uma planta medicinal perene que cresce em lugares úmidos, em geral onde a luz é escassa. Originária da Inglaterra, Europa central e meridional, pertence à família Adiantaceae. Possui compostos fenólicos como o ácido gálico, mucilagens, taninos, carboidratos, diversos princípios amargos como a capilarina e pequena quantidade de óleo essencial (TESKE; TRENTINI, 1997; ProenÇA et al., 2003). É tradicionalmente usada como planta medicinal para uso expectorante, diurético, tônico capilar, infecções com catarro, doenças do tórax, tratamento de tumor no baço e possui propriedades anticancerígenas (GuHA et al., 2005). Extratos utilizando partes aéreas desta planta foram testados apresentando efeito antifúngico (GuHA et al., 2005), inclusive contra Candida albicanis (EzZAT, 2001) e antibacteriano contra Bacillus subtilis, Escherichia coli, S. aureus, Proteus vulgaris e Pseudomonas aeruginosa (RAINTREE, 2006).

O objetivo deste trabalho foi verificar a atividade antimicrobiana de derivados obtidos de avenca contra os fungos Phakopsoraeuvitis, Pseudocercosporavitis, Sclerotium rolfsii e Colletotrichum musae e as bactérias Erwinia sp. e Bacillus subtilis.

\section{MATERIAL E MÉTODOS}

\section{Obtenção do extrato e preparo dos tratamentos}

O extrato foi obtido a partir de folhas da planta medicinal Adiantum capillus-veneris (avenca), cultivada em latossolo eutroférrico em condições de sombreamento natural. As folhas, coletadas nos meses de outubro e novembro, foram secas por 10 dias em ambiente sombreado earejado à temperatura de $25^{\circ} \mathrm{C}$, trituradas em moinho para obtenção do pó vegetal e conservadas em local fresco ao abrigo da luz (Teske; TRentini, 1997). Os tratamentos foram obtidos por infusão, decocção e maceração. Para infusão, ferveu-se a água destilada previamente e logo após adicionou-se o pó da planta, deixando-se agir por 10 min em recipiente fechado. Na decocção colocou-se o pó em água destilada fria, aquecendo até a ebulição e deixando ferver por $1 \mathrm{~min}$ e, em seguida, reservou-se em recipiente fechado por 10 min. Para o preparo da maceração diluiu-se o pó com água fria destilada e reservou-se em recipiente fechado por $24 \mathrm{~h}$. Os tratamentos foram filtrados com gaze. Para os tratamentos autoclavados, os extratos foram incorporados aos meios de cultura usados nos ensaios e foram autoclavados por $20 \mathrm{~min}$ a $120^{\circ} \mathrm{C}$ e $1 \mathrm{~atm}$, enquanto que para a condição não autoclavada, os tratamentos foram centrifugados por $15 \mathrm{~min}$ a $6.500 \mathrm{~g}$, em seguida filtrados em papel Whatman $\mathrm{n}^{\circ} 40 \mathrm{e}$, posteriormente, esterilizados em membrana Millipore com $0,45 \mu \mathrm{m}$ de diâmetro de poro.

\section{Atividade antifúngica}

Foi avaliada a atividade antifúngica sobre a germinação de esporos e o crescimento micelial de fungos fitopatogênicos. Avaliou-se a inibição da germinação de esporos microscopicamente sobre urediniósporos do fungo $P$. euvitis, agente causal da ferrugem da uva, e dos conídios do fungo $P$. vitis, agente causal da mancha das folhas da videira. Para o ensaio com $P$. euvitis, os urediniósporos foram removidos de folhas de videira com pincel e fez-se uma suspensão de esporos com água destilada $(2 \mathrm{x}$ $10^{4}$ urediniósporos $/ \mathrm{mL}$ ). Uma alíquota de $50 \mu \mathrm{L}$ da 
solução foi colocada em uma lâmina contendo uma camada delgada com $700 \mu \mathrm{L}$ de meio ágar-água $1 \%$ autoclavado, que, conforme ensaios preliminares, foi o melhor substrato para germinação desses esporos. Cadalâmina foi reservada individualmenteem placas dePetricontendo papel, para germinação, umedecido comágua destilada esterilizada. Sobre a suspensão de esporos foram adicionados $50 \mu \mathrm{L}$ de cada tratamento. As placas foram mantidas em escuro por $6 \mathrm{~h}$, quando receberam $20 \mu \mathrm{L}$ de azul algodão com lactofenol para paralisar a germinação (NARUZAWA et al., 2006). A avaliação dos urediniósporos germinadosfoi realizada em microscópio óptico. Para o ensaio com $P$. vitis os conídios foram retirados de folhas de videira a partir de lesões típicas e colocados em água destilada para obter suspensão com $2 \times 10^{4}$ conídios/mL. Oensaio foi realizadoem placas de testeElisa, devidoà praticidade deste método e ao fato desses esporos germinarem nesta condição. Para tanto, foram adicionados $40 \mu \mathrm{L}$ de tratamento e $40 \mu \mathrm{L}$ da suspensão de esporos em cada orifício da placa. As placas foram mantidas no escuro à temperatura ambiente por 24h. Após isso, foram acrescidos $20 \mu \mathrm{L}$ deazulalgodãocomlactofenol para paralisação da germinação. Asconcentrações dos tratamentos para ambos os ensaios foram de $0,25 \%$, $0,5 \%, 1,25 \%, 2,5 \%, 5 \%, 10 \%$ e $20 \%$. Foram utilizadas, para ambos os ensaios quatro repetições para cada concentração de cada tratamento, tendo como testemunhas água destilada e o fungicida Azoxystrobin $(0,024 \mathrm{~g} / 100 \mathrm{~mL})$.

O crescimento micelial foi avaliado sobre $C$. musae e $S$. rolfsii, agentes causadores da antracnose em banana e da murcha de sclerotium da soja, respectivamente. Os tratamentos foram incorporados diretamente ao meio de cultura nas concentrações de $0,1 \%, 0,5 \%, 1 \%, 2,5 \%, 5 \%, 10 \%$ e $20 \%$ e autoclavadosa $120^{\circ} \mathrm{C} \mathrm{e} 1 \mathrm{~atm}$ por $20 \mathrm{~min}$. Uma hora após o meio ter sido vertido em placas de Petri, um disco de $8 \mathrm{~mm}$ de diâmetro, contendo micélio de $C$. musae ou de $S$. rolfsii, com 7 dias deidade em BDA, foi repicado para ocentro das placas, as quais foram vedadas com filme plástico e mantidas a $25^{\circ} \mathrm{C}$. Foram utilizadas quatro repetições por tratamento. Os tratamentos controle continham apenas BDA ou o fungicida Azoxystrobin $(0,024 \mathrm{~g} / 100 \mathrm{~mL})$. As avaliações foram realizadas por medições do diâmetro das colônias (média de duas medidas diametralmente opostas) após 5 dias para S. rolfsii e após 7 dias para C. musae. Após 16 dias foram contadas as estruturas de resistência (escleródios) de S. rolfsii.

\section{Atividade antibacteriana}

As bactérias B. subtilis (isolada de sementes de soja com sintomas de podridão) e Erwinia sp. (isolada de frutos de pimentão com podridão) foram cultivadas em meio ágar nutriente, à temperatura de $+/-25^{\circ} \mathrm{C}$.
A partir de colônias jovens (com 24h), foi preparada uma suspensão $\left(1 \times 10^{8}\right.$ bactérias $\left./ \mathrm{mL}\right)$ com solução salina $(0,85 \%$ de $\mathrm{NaCl})$ estéril. Para os ensaios foram utilizados tubos de ensaio contendo caldo nutriente acrescido dos tratamentos (concentrações de $0,25 \%$, $0,5 \%, 1,25 \%, 2,5 \%, 5 \%, 10 \%$ e $20 \%$ ), totalizando $5 \mathrm{~mL}$ por tubo. A concentração dos nutrientes do meio foi a mesma para todos os tratamentos. Foram transferidos $50 \mu \mathrm{L}$ de cada suspensão bacteriana em cada tubo de ensaio, com três repetições, utilizando-se um quarto tubo sem bactéria para leitura de absorbância (branco). Constituíram testemunhas o meio de cultura e meio de cultura acrescido de antibiótico $(22,5 \mathrm{mg} / \mathrm{L}$ de oxitetraciclina e $225 \mathrm{mg} / \mathrm{L}$ de estreptomicina). Os tubos foram mantidos sob agitação por $42 \mathrm{~h}$, à temperatura $+/-25^{\circ} \mathrm{C}$, com posterior leitura de absorbância a $580 \mathrm{~nm}$ (MотоYAмA et al., 2003).

Os resultados foram avaliados no programa estatístico "Estat", a partir do comportamento da curva de regressão, considerando os valores do coeficiente de determinação $\left(R^{2}\right)$ com $5 \%$ de significância.

\section{RESULTADOS E DISCUSSÃO}

\section{Atividade antifúngica}

No ensaio de germinação de esporos de $P$. euvitis (Fig. 1) não autoclavado, os tratamentos obtidos por infusão e maceração obtiveram equação linear com valores de $\mathrm{R}^{2}$ de 0,46 e 0,88 , respectivamente, enquanto que por decocção foi significativa a função quadrática com valor de $R^{2}$ de 0,76. Nesse caso, maior inibição da germinação ocorreu com a concentração de $13,5 \%$, que reduziu em $59 \%$ a germinação em relação à testemunha água. Para os tratamentos não autoclavados de infusão e maceração, a inibição de esporos foi iniciada a $1,25 \%$, sendo que na concentração de $20 \%$ houve redução de $63 \%$ e $75 \%$, respectivamente, apresentando nestes dois casos possível efeito de dose dependência. No ensaio autoclavado, os tratamentos obtidos por infusão e decocção tiveram função quadrática com valores de $R^{2}$ de 0,98 e 0,80 , respectivamente. O macerado autoclavado não teve resultado significativo. Os tratamentos infusão e decocção autoclavados apresentaram pequeno incremento na porcentagem de germinação em baixas concentrações, mas reduziram a germinação a partir de $12 \%$ e $14 \%$, respectivamente, podendo atingir a máxima inibição $(100 \%)$, considerando a tendência da curva, nas concentrações de $39 \%$ e $34 \%$, respectivamente. Quando comparados os derivados autoclavados com não autoclavados observa-se a tendência de menor atividade antifúngica para os três derivados autoclavados, indicando a possível presença de compostos termolábeis ou sensíveis ao tratamento térmico (FRANZENER et al., 2003). 
Autoclavado
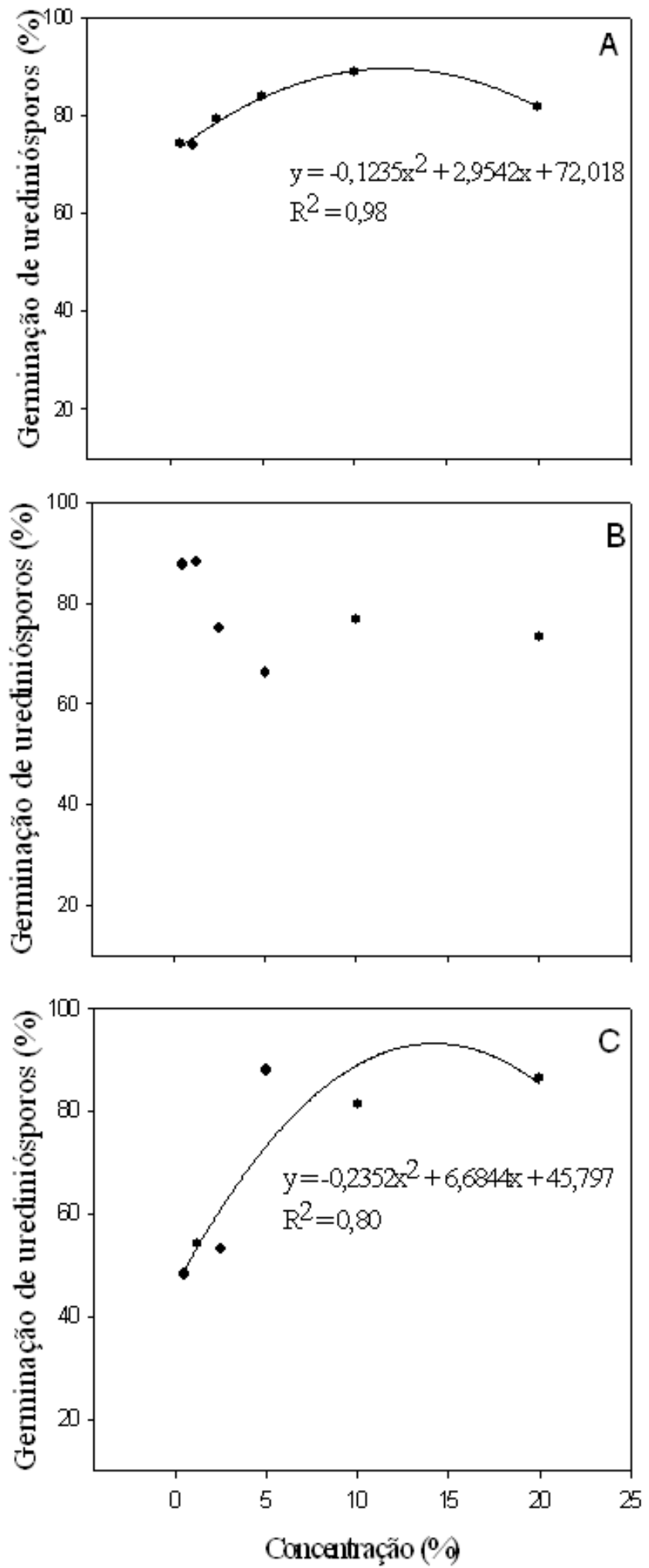

Não Autoclavado
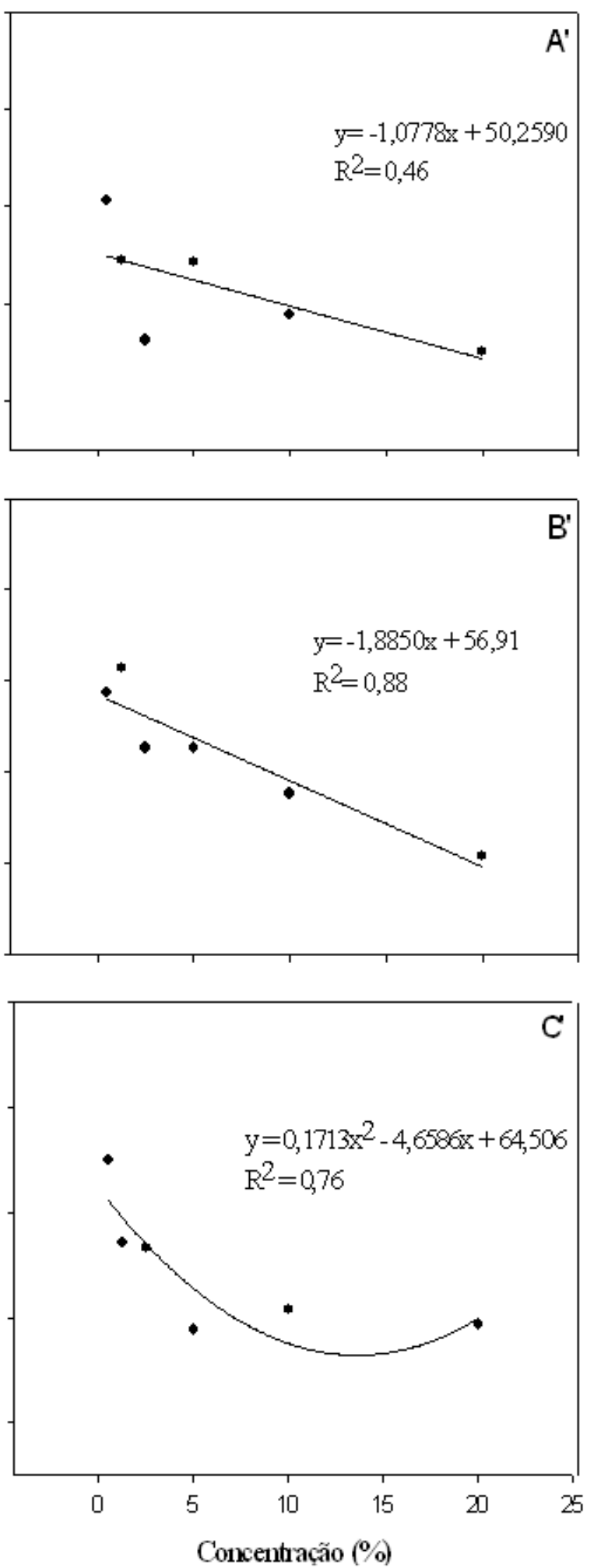

Fig. 1 - Germinação in vitro de urediniósporos de Phakopsora euvitis na presença de derivados de A. capillus-veneris obtidos por infusão (A e A'), maceração (B e B') e decocção (C e $\left.C^{\prime}\right)$. 
Autoclavado
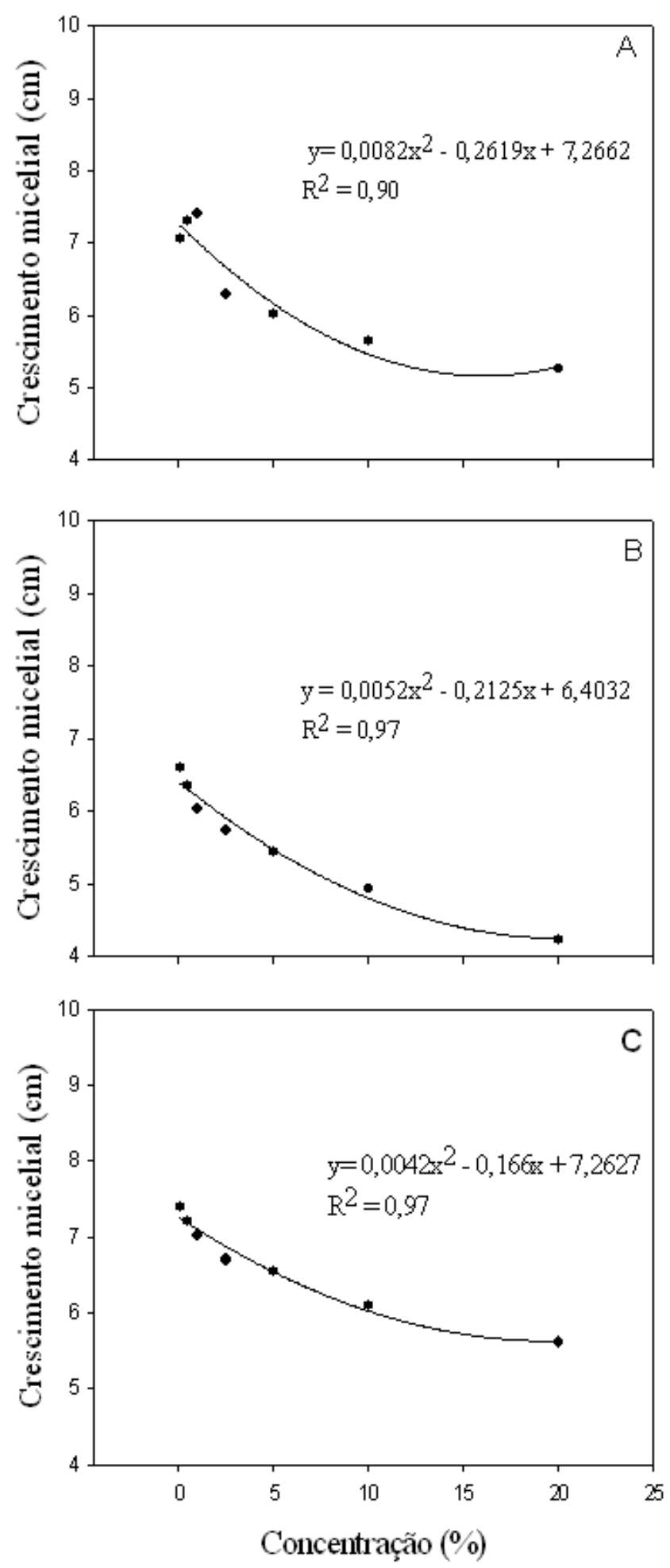

Não Autoclavado
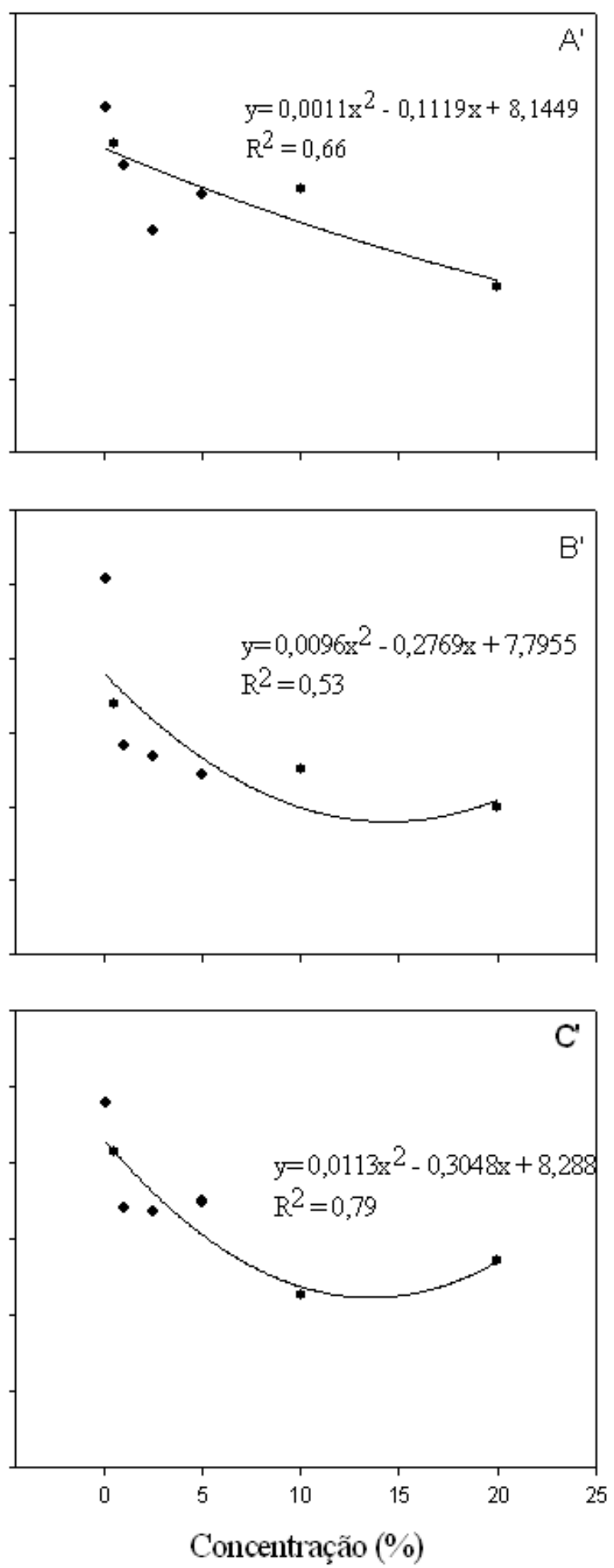

Fig. 2 - Germinação in vitro de conídios de Pseudocercospora vitis, na presença de derivados de A. capillus-veneris obtidos por infusão (A e $\left.A^{\prime}\right)$, maceração (B e B') e decocção (C e $\left.C^{\prime}\right)$. 

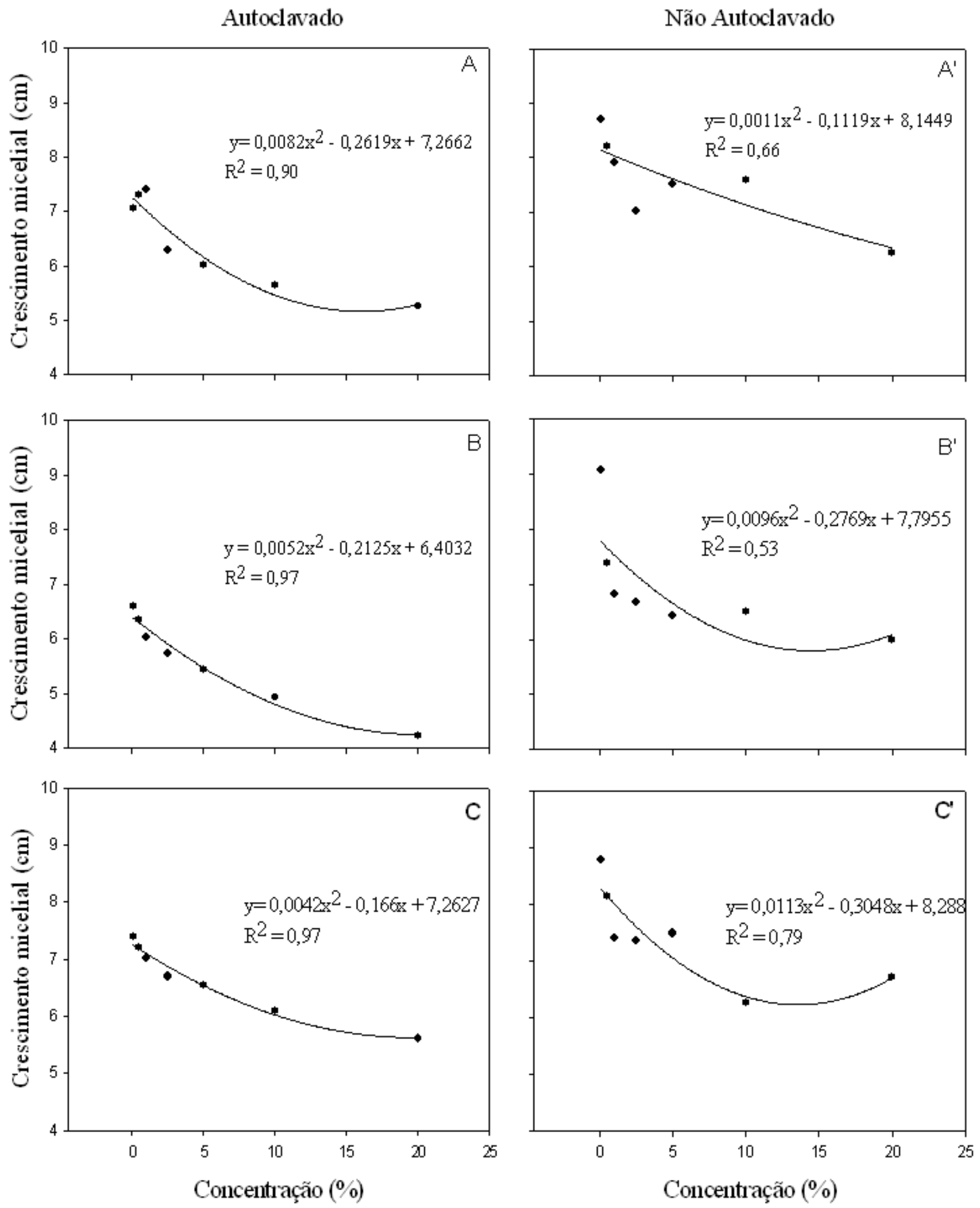

Fig. 3 - Crescimento micelial in vitro de Colletotrichum musae, na presença de derivados de A. capillus-veneris obtidos por infusão (A e $\left.A^{\prime}\right)$, maceração (B e B') e decocção ( $C$ e $\left.C^{\prime}\right)$. 

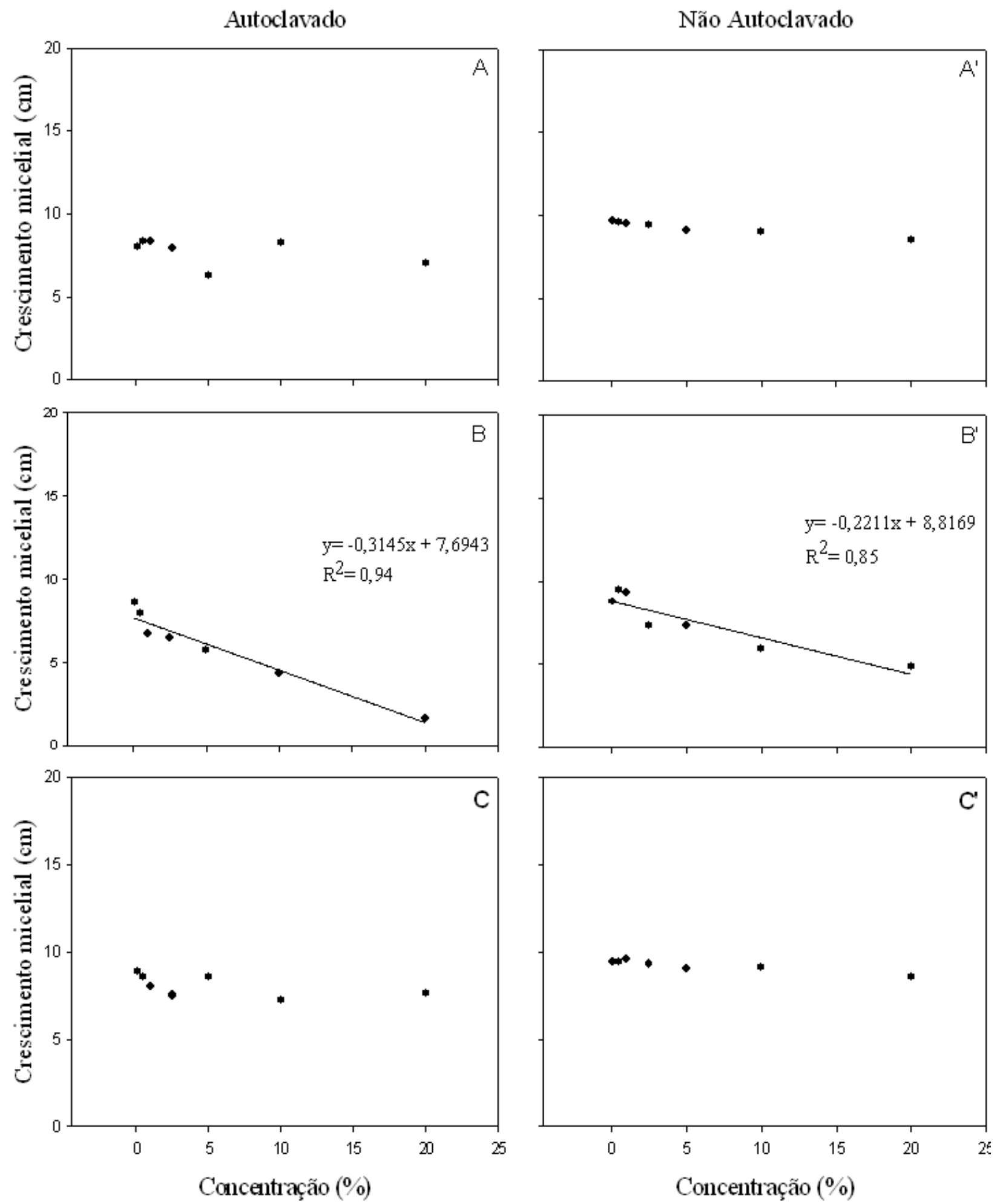

Fig. 4 - Crescimento micelial in vitro de Sclerotium rolfsii, na presença de derivados de A. capillus-veneris obtidos por infusão (A e $\left.A^{\prime}\right)$, maceração (B e B') e decocção (C e $\left.C^{\prime}\right)$. 
Para o fungo $P$. vitis (Fig. 2) os tratamentos autoclavados e não autoclavados tiveram valores de $\mathrm{R}^{2}$ ajustados variando de 0,86 a 0,99 . Os tratamentos não autoclavados e o obtido por infusão autoclavado tiveram função linear iniciando a inibição da germinação de conídios na concentração de 5\%. Decocçãoe o macerado autoclavados tiveram função quadrática. Considerando a concentração de $20 \%$, a diminuição de conídios germinados foi de 21, 24 e 99\% para infusão, decocção e maceração, respectivamente. A inibição de germinação de conídios iniciou-se com a concentração de $0,25 \%$ para maceração e decocção autoclavados, tendo maior inibição nas concentrações de $17 \%$, com redução de $53 \%$ e $70 \%$, para os respectivos tratamentos em relação a testemunha água. Para $P$. vitis, no entanto, não foi observada redução na atividade antifúngica em função do tratamento térmico por autoclavagem como ocorreu para $P$. euvitis, indicando ser tal atividade mais complexa e variável conforme o organismo em estudo.

No ensaio decrescimento micelial de C. musae (Fig. 3) os tratamentos autoclavados tiveram equações quadráticas ajustadas com valores de $\mathrm{R}^{2}$ variando de 0,90 a 0,97 . Para maceração a redução em relação ao controle BDA foi iniciada a $0,1 \%$, enquanto que para decocção einfusão foi a partir de 2,5\%. Considerandose as equações, o crescimento micelial foi menor nas concentrações de $16 \%$, 20\% e 20,5\% para infusão, decocção e maceração, respectivamente. O derivado obtido por maceração teve redução de 39,3\% em relação ao controle BDA, infusão teve redução de $26 \%$ e decocção $19 \%$. Os tratamentos que não foram autoclavados também tiveram funções quadráticas com valor de $\mathrm{R}^{2}$ variando de 0,53 a 0,79 . Nos tratamentos não autoclavados, para maceração a redução em relação ao controle foi a partir da concentração de $1 \%$, para infusão foi a partir de $20 \%$ e para decocção foi a partir de $10 \%$. Conforme as equações, os menores crescimentos foram obtidos para as concentrações de $14 \%$ e $13 \%$ para maceração e decocção, respectivamente e considerando a tendência do gráfico, para a concentração de $54 \%$ de infusão, com redução de crescimento de 29, 17 e $11 \%$, respectivamente, em relaçãoà testemunha água. Embora alguns derivados tenham apresentado função quadrática, não é possível afirmar que eles tenham sua atividade reduzida em elevadas concentrações situadas fora do intervalo em estudo, mas possivelmente ocorra estabilização da atividade em maiores concentrações.

O crescimento micelial de S. rolfsii (Fig. 4) foi inibido apenas na presença do derivado obtido por maceração, tanto autoclavado quanto não autoclavado, com função linear com valores de $\mathrm{R}^{2}$ de 0,94 a 0,84 , respectivamente. $\mathrm{O}$ macerado autoclavado inibiu o crescimento micelial em $83 \%$ na concentração de $20 \%$ do derivado, enquanto que o não autoclavado inibiu $47 \%$ para a mesma concentração. A partir desses dados é possível destacar a atividade do derivado obtido por maceração e que, provavelmente, a autoclavagem seja capaz de liberar ou alterar moléculas, melhorando a sua atividade antimicrobiana. Adicionalmente, talvez o maior tempo de permanência do solvente água com o material vegetal tenha favorecido a extração de compostos antimicrobianos, embora não foram encontradas na literatura informações nesse sentido.

A quantidade de estruturas de resistência (escleródios) de $S$. rolfsii apresentou redução média de 21 \% para o macerado autoclavado e de $34 \%$ para a decocção Já para os tratamentos não autoclavados houve redução média na produção de escleródios de 51, 47 e 27\% para infusão, maceração e decocção, respectivamente, sobretudo em maiores concentrações. Embora a autoclavagem tenha promovido variações, não foram observadas alterações drásticas como as observadas com outros extratos aquosos de plantas medicinais, estimulando (BONALDO et al., 2004) ou inibindo (FRANZENER et al., 2003) a atividade antimicrobiana. Assim, para os derivados de avenca testados, a autoclavagem não comprometeu o seu potencial antimicrobiano.

Embora sejam escassas informações sobre a atividade antifúngica da avenca, GUHA et al. (2005) relataram que extratos aquosos e fenólicos mostraram-se bioativos contra os fungos Aspergillus niger e Rhizopus stolonifer.

\section{Atividade antibacteriana}

Para Erwinia sp., os resultados não foram significativos, exceto para o macerado autoclavado, que teve função quadrática com valor de $\mathrm{R}^{2} \mathrm{de} 0,78$, tendo inibição a partir da concentração de $10 \%$ e atingindo 99\% de redução do crescimento bacteriano para a concentração de $20 \%$ (como apenas este tratamento foi significativo, os gráficos não foram apresentados). Para B. subtilis, os tratamentos autoclavados e não autoclavados não tiveram resultados significativos ou de atividade inibitória.

$\mathrm{Na}$ literatura, no entanto, pode-se encontrar resultado diferente quando se utilizam outros tipos de solventes. Extratos obtidos com hidróxido de metanol, de partes aéreas da avenca, mostraram-se ativos contra $B$. subtilis, na dosagem de $0,5 \mathrm{mg} / \mathrm{mL}$, E. coli, S. aureus a $1,0 \mathrm{mg} / \mathrm{mL}$ e para $P$. vulgaris e $P$. aeruginosa na dosagem 2,0 mg/mL (RAINTREE, 2006).

Avancini et al. (2000), avaliando a atividade do decocto de $B$. trimera (carqueja) sobre bactérias de interesse veterinário, relataram que, diferentemente dos resultados obtidos neste trabalho, as bactérias Gram-positivas foram mais sensíveis ao derivado que as Gram-negativas. Os mesmos autores citam que a presença de atividade significativa de derivados aquosos mostra que suas substâncias antimicrobianas 
são também hidrossolúveis, indicando ser correta sua extração dessa forma simplificada.

\section{CONCLUSÃO}

Todos os derivados apresentaram atividade antifúngica, sugerindo ser correta esta forma de extração, porém maceração não autoclavado foi o mais eficiente contra os fungos $P$. euvitis e $P$. vitis. $\mathrm{O}$ macerado autoclavado foi o mais eficiente contra $C$. musae e S. rolfsii e para a bactéria Erwinia sp. Contra a bactéria $B$. subtilis, nenhum dos tratamentos testados foi eficiente. O tratamento térmico por autoclavagem promoveu alterações, mas não comprometeu o potencial antimicrobiano dos derivados. Os ensaios realizados indicam o potencial da planta $A$. capillus-veneris no controle de fitopatógenos fúngicos e bacterianos, sobretudo pelo derivado obtido por maceração, viabilizando a realização de ensaios in vivo com essa finalidade.

\section{AGRADECIMENTOS}

Os autores agradecem ao professor Jerry Johann pela consultoria estatística e à Secretaria de Ciência, Tecnologia e Ensino Superior (SETI) - Fundo Paraná (CT 17/07) pelo auxílio financeiro.

\section{REFERÊNCIAS}

AVANCINI, C.A.M.; WIEST, J.M.; MUNDSTOCK, E. Atividade bacteriostática e bactericida do decocto de Baccharis trimera (Less.) D.C., Compositae, carqueja, como desinfetante ou anti-séptico. Arquivo Brasileiro de Medicina Veterinária e Zootecnia, v.52, n.3, p.230-234, 2000.

BALBI-PEÑA, M. I.; BECKER, A.; STANGARLIN, J.R.; FRANZENER, G.; LOPES, M.C.; SCHWAN-ESTRADA, K.R.F. Controle de Alternaria solani em tomateiro por extrato de Curcuma longa e curcumina- I. Avaliação in vitro. Fitopatologia Brasileira, v.31, n.3, p.310-314, 2006.

BONALDO, S.M.; SCHWAN-ESTRADA, K.R.F.; STANGARLIN, J.R.; TESSMANN, D.J.; SCAPIM, C.A. Fungitoxicidade, atividade elicitora de fitoalexinas e proteção de pepino contra Colletotrichum lagenarium, pelo extrato aquoso de Eucalyptus citriodora. Fitopatologia Brasileira, v.29, n.2, p.128-134, 2004.

BORÉM, A. Melhoramento de plantas. 3.ed. Viçosa: UFV, 2001. 500p.

ESTAT v.2.0: Sistema de Análise Estatística, Software. Jaboticabal, SP: Depto de Ciências Exatas, Faculdade de Ciências Agrárias e Veterinárias, Univ. Estadual Paulista, 1992.
EZZAT, S.M. In vitro inhibition of Candida albicans growth by plant extracts and essential oils. World Journal of Microbiology E Biotechnology, v.17, p.757-759, 2001.

FIORI, A.C.G.; SCHWAN-ESTRADA, K.R.F.; STANGARLIN, J.R.; VIDA, J.B., SCAPIM, C.A.; CRUZ, M.E.S.; PASCHOLATI, S.F. Antifungal activity of leaf extracts and essential oils of some medicinal plants against Didymella bryoniae. Journal of Phytopathology, v.148, p.483-487, 2000.

FRANZENER, G.; STANGARLIN, J.R.; SCHWANESTRADA, K.R.F.; CRUZ, M.E.S. Atividade antifúngica e indução de resistência em trigo a Bipolaris sorokiniana por Artemisia camphorata, Acta Scientiarum, v.25, n.2, p.503-507, 2003.

GHINI, R.; KIMATI, H. Resistência de fungos a fungicidas. Jaguariúna, SP: Embrapa Meio Ambiente, 2000. 78p.

GUHA, G.P.; MUKHOPADHYAY, R; GUPTA, K. Antifungal activity of the crude extracts and extracted phenols from gametophytes and sporophytes of two species of Adiantum. Taiwania, v.50, n.4, p.272-283, 2005.

KUHN, O.J.; PORTZ, R.L., STANGARLIN, J.R., DEL ÁGUILA, R.M., SCHWAN-ESTRADA, K.R.F.; FRANZENER, G. Efeito do extrato aquoso de cúrcuma (Curcuma longa) em Xanthomonas axonopodis pv. manihotis. SeminaCiências Agrárias, v.27, n.1, p.13-20, 2006.

MOTOYAMA, M.M.; SCHWAN-ESTRADA, K.R.F.; STANGARLIN, J.R.; FIORI, A.C.G.; SCAPIM, C.A. Efeito antimicrobiano de extrato cítrico sobre Ralstonia solanacearum e Xanthomonas axonopodis pv. Manihotis. Acta Scientiarum Agronomy, v.25, n.2, p.509-512, 2003.

NAKASONE, A.K.; BETTIOL, W.; SOUZA, R.M. The effect of water extracts of organic matter on plants. Summa Phytopathologica, v.25, n.4, p.330-335, 1999.

NARUZAWA, E.S.; CELOTO, M.I.B.; PAPA, M.F.S; TOMQUELSKI, G.V.; BOLANI, A.C. Estudos epidemiológicos e controle químico de Phakopsora euvitis. Fitopatologia Brasileira, v.31, n.1, p.41-45, 2006.

PROENÇA, A.C.; ROQUE, A.P.; RODRIGUES, O. Plantas e produtos vegetais em fitoterapia. Lisboa: Fundação Calouste Gulbenkian, 2003. 701p.

RAINTREE, N. Biological activity for extracts of avenca (Adiantum capillus-veneris). Disponível em: <http//:www.rain-tree.com/avenca-activity.pdf>. Acesso em: 11 set. 2006.

RODRIGUES, E.; SCHWAN-ESTRADA, K.R.F.; STANGARLIN, J.R.; CRUZ, M.E.S.; FIORI-TUTIDA, A.C.G. Avaliação da atividade antifúngica de extratos de gengibre e eucalipto in vitro e em fibras de bananeira infectadas com Helminthosporium spp. Acta Scientiarum Agronomy, v.28, n.1, p.123-127, 2006. 
SCHWAN-ESTRADA, K.R.F.; STANGARLIN, J.R.; CRUZ, M.E.S. Uso de plantas medicinais no controle de doenças de plantas. Fitopatologia Brasileira, v.8, p.54-56, 2003

SCHWAN-ESTRADA, K.R.F.; STANGARLIN, J.R. Extratos e óleos essenciais de plantas medicinais na indução de resistência. In: CAVALCANTI, L.S.; DI PIERO, R.M.; CIA, P.; PASCHOLATI, S.F.; RESENDE, M.L.; ROMEIRO, R.S. (Ed.). Indução de resistência em plantas a patógenos e insetos. Piracicaba: FEALQ, 2005. p.125-138.
STANGARLIN, J.R.; SCHWAN-ESTRADA, K.R.F.; CRUZ, M.E.S.; NOZAKI, M.H. Plantas medicinais e controle alternativo de fitopatógenos. Biotecnologia, Ciência e Desenvolvimento, v.11, p.16-21, 1999.

TESKE, M.; TRENTINI, A.M.M. Compêndio de fitoterapia. Curitiba: Herbarium, Laboratório Botânico, 1997. 317p.

Recebido em 20/1/09

Aceito em 14/7/10 